CARPATHIAN JOURNAL OF FOOD SCIENCE AND TECHNOLOGY

journalhomepage:http://chimie-biologie.ubm.ro/carpathian_journal/index.html

\title{
THE EFFECT OF BALANGU SHIRAZI (LALLEMANTIA ROYLEANA) GUM ON THE QUALITY OF GLUTEN-FREE PAN BREAD CONTAINING PRE- GELATINIZED SIMPLE CORN FLOUR WITH MICROWAVE
}

\author{
Mahdi Jalali $^{1}$, Zahra Sheikholeslami2 ${ }^{*}$, Amir Hossein Elhamirad ${ }^{3}$, Mohammad Hossein Haddad \\ Khodaparast $^{4}$, Mahdi Karimi ${ }^{5}$ \\ ${ }^{1,3}$ Department of Food Science and Technology, Sabzevar Branch, Islamic Azad University, Sabzevar, Iran \\ ${ }^{2,5}$ Agricultural engineering research department. Khorasan Razavi agricultural and natural Resources research \\ and education center, Agriculture Research, Education and Extension Organization (AREEO) Mashhad, Iran \\ ${ }^{4}$ Department of Food Science and Technology, Ferdowsi University of Mashhad, Mashhad, Iran \\ *shivasheikholeslami@yahoo.com
}

https://doi.org/10.34302/crpjfst/2019.11.2.6

\begin{tabular}{l} 
Article history: \\
Received: \\
25 August 2018 \\
Accepted: \\
$\quad 1$ March 2019 \\
\hline Keywords: \\
Electronic microscope \\
Image processing \\
Local gum \\
Microwave \\
Pre-gelatinized flour
\end{tabular}

Article history:

25 August 2018

cepted:

Keywords:

Electronic microscope

Image processing

Pre-gelatinized flour

\begin{abstract}
In this study, pre-gelatinized simple corn flour with microwave and three levels of Balangu Shirazi gum were used in producing gluten free bread. The substructure of two types of flour was evaluated using the electronic microscope. The properties of bread samples including moisture, specific volume, porosity, crust color, texture and overall acceptance were studied. The results of electronic microscope showed that the granular structure of corn flour was coherent. However, the granular structure of pre-gelatinized corn flour had more structural expansion and swell because of demolished heat. In addition, samples containing pre-gelatinized corn flour and $2 \%$ Balangu Shirazi gum had the highest humidity in the first $(22.5 \%)$ and third $(19.4 \%)$ day. The highest porosity $(23.3 \%$ and $23.5 \%)$ and specific volume (4.9 and $5.1 \mathrm{~cm}^{3} / \mathrm{g}$ ) and the minimal texture firmness were observed within 1 day after manufacturing (4.8 \& 4.9 Newton) in samples containing pregelatinized corn flour and two levels of Balangu Shirazi gum (1\% and $2 \%$ ). Moreover, the results showed that increased L* colorful component $(52 \%$ increase) caused by using the pre-gelatinized corn flour and raising the consumption level of gum. The presence of gum didn't have a significant impact on two colorful components such as $a^{*}$ and $b^{*}$. The use of pregelatinized corn flour resulted in decreasing $b^{*}$ colorful component. Also, sensory evaluations gave the highest score of overall acceptance to samples containing pre-gelatinized corn flour and two levels of Balangu Shirazi gum $(1 \%$ and $2 \%)$.
\end{abstract}

\section{Introduction}

Celiac disease is an autoimmune digestive disorder that created by the consumption of wheat gliadin, rye prolamin (secalin), barley (hordein) and oat (avenin). If a patient has a gluten-free diet continuously, an appropriate outcome is achieved through mucus and clinical improvement (Hamaker Bruce, 2008).

Gluten is an essential protein in forming the structure of flour and makes the elastic characteristics of bread dough. It has a role in the appearance and internal texture of many bakery products (Lopez et al., 2004). Removing this 
protein from wheat flour or using gluten-free flours like corn, rice, millet, sorghum and so on in formulation of bread, cake, biscuits, muffin and other bakery products makes an important appearance and technological problems and results in decreased product marketing (Gallagher et al., 2004). In the segmentation of starch types, which include varieties of cereals, roots and tubers and the waxy, corn and wheat are in one group, namely, starch from cereals. The study of granular characteristics such as granule type and diameter, morphology, gelatinization temperature, amylose content, and baking characteristics indicate a high similarity between corn starch and wheat starch (Swinkels, 1985).

In the field of gluten-free products, food industry researchers commonly advice producers to use types of additives in order to solve this problem and follow the gluten's properties. On the other hand, promoting consumers' awareness about damages caused by chemical additives and trend toward natural and local additives to make nutritive and community health have been increased.

Balangu Shirazi (Lallemantia royleana) is one of these additives that extracted from local seeds. Benth plant Lellemantia royleana (Benth. In Walla) which is known as Balangu Shirazi in the Persian language belongs to dicotyledon class, sympetalous subclass, lamiaceae order, mint family and lallemantia genus. Mint family has a good distribution in different areas of Iran with 46 genera and 410 species and subspecies (Naghibi et al., 2005). Dark and oval seeds of this plant have completely two distinct dorsal and inner surfaces which covered by many tiny hollows. The dorsal surface is convex and has four or five subtle vertical lines. The inner surface has a distinguished vertical prominence in the middle. The narrower part of the inner surface is dent and has a small round and white buttony prominence (the junction of seed and the axis of an ovary) exactly at the top of the prominent midline and terminal edge (Razavi et al., 2008). Balangu's seed is a rich source of fiber, oil and protein has a healthy, nutritive and pharmacological effects (Naghibi et al., 2005). It creates a sticky and cloudy liquid in the water which has no taste (Razavi et al., 2008). It's applied to various traditional products like icecream, bread in Iran and Turkey and a kind of juice (chia) (Razavi and Karazhiyan, 2009). In addition, aromatic seeds of this plant are traditionally used in the treatment of failures such as gum bleeding, coughs caused by a cold and kidney problems and also applied as a pain relief, sedative, stimulant, and diuretic drug due to having mucilage.

Despite the use of additives as a gluten replacement, gluten-free products or those containing weak flour have stiff or dry texture. Also, the duration of their maintenance is short and become stale very soon. These products have no taste and scent and have a wrinkled and colorless crust. They're not acceptable for consumer (Sahraiyan et al., 2013). Different methods are recommended to decrease staling and improve the texture of these types of products like using flour and pre-gelatinized starch. Pre-gelatinized starch is one type of modified starches which sometimes called instant starch. To produce instant starch, first, natural starch is gelatinized and then changed to dry powder. An important difference between thermally modified starches and chemical modified ones is that increased viscosity would be made more quickly in gelatinized type. It means that they rapidly absorb water like a sponge (Anastasiades et al., 2002).

One of the thermal methods is to use microwave's waves to produce modified starches. These waves are a part of an electromagnetic spectrum that has 300-300000 $\mathrm{MHz}$ frequency. They're placed between dielectric and infrared waves in an electromagnetic spectrum (Zhongdong et al., 2005). However, microwave's waves have been applied for household uses more than half of the century, industrial uses of them have been limited to the recent years only (Vadivambal and Jayas, 2007). In a conventional thermal method, the heat is transferred from the warm point to cool spot which leads to increase temperature 
and warm up substances gradually. In the thermal method with microwave, severe vibration oscillations were generated in bipolar molecules and ions. Interaction of these molecules with each other leads to increase foodstuff temperature very rapidly. On the other hand, warming up the foodstuff is accelerated quickly. So, thermal processing in the microwave is an effective factor to reduce waste of energy and time because of warming up the inner parts of foodstuff (Bilbao-Sainz et al., 2007; Zylema et al., 1985).

Zylema et al. (1985) compared the granular structure of the starch system in the water during thermal processing in the microwave and showed that there is no difference between the size of swell in samples heated by microwave and those heated by the conventional method under the condition the heat is equal. But, the time and energy were saved. In the case of microwave application, the amylose content, particle size diameter, pasting temperature and gelatinization temperature increase and parameters such as pasting viscosity, and solubility of all the heat-treated starches are reduced. Of course, it should be noted that due to the application of both types of microwave heating and conventional heating, changes in the structure of starch granules, loss of birefringence, rupture of granules and leakage of the constituent of starch occur (Uthumporn et al., 2016). Ndife et al. (1998) studied how to be gelatinized different starches' granule during heating in the microwave. They presented a quantitative model to designate the relation between gelatinization of granules and existing water content. Moreover, relatively wide researches have been performed about physicochemical properties and molecules and modification of different starches using the thermal processing with microwave (Anderson and Guraya, 2006; Horchani et al., 2010). Various studies have shown that pregelatin corn flour has a good ability to swell in cold water, which makes it easier for consumers to pregelatinized corn flour powder to be bake at a lower temperature (Joshi et al., 2014;
Jiamjariyatam et al., 2015). So in this study, given the society need to gluten-free products with desirable sensory characteristics and texture, corn flour (pre-gelatinized flour with microwave or simple flour) and local gum of Iran (Balangu Shirazi) were used to produce gluten free bread and gluten free samples compared to the bread containing wheat flour.

\section{Materials and methods \\ 2.1. Materials}

Corn flour with $9.3 \%$ moisture, $9.4 \%$ protein, $3.3 \%$ fat and $2.6 \%$ ash was provided by Golha manufactory (Tehran-Iran). For this purpose, needed flour was prepared to do an examination and maintained in the fridge at $4^{\circ \mathrm{C}}$. Also, yeast (Saccharomyces cerevisiae) that was in the form of active dry yeast powder and packed as a vacuum, supplied by Razavi Yeast company (Mashhad, Iran). Other products like lecithin powder, albumen powder, Balangu Shirazi seed and sugar, salt and vegetable oil were supplied by Toosarjan company (Mashhad, Iran), Golpoodr Golestan company (Gorgan, Iran), local market and stores with confectionary raw materials, respectively. Other chemical substances were provided by Merck company (Germany).

\subsection{Preparation of pre-gelatinized corn flour with microwave}

Majzoobi and Farahanky method (2008) was used with changes to produce pregelatinized corn flour. In this method, $12 \mathrm{~g}$ flour was poured within $20 \mathrm{ml}$ water inside the glass container and mixed for five minutes at the temperature of $55^{\circ \mathrm{C}}$ in the hot water (W350b model, Electronic Fater Company of Iran). Then, the obtained mixture was placed into the household microwave (LGMC-789Y, made in Korea) with the $360 \mathrm{~W}$ power and $2450 \mathrm{MHz}$ frequency for five minutes until it dried. Finally, the produced sample was ground and sieved until a complete homogeneous powder obtained. 


\subsection{Preparation of images from substructure of corn flour (simple and pre-gelatinized) with the electronic microscope}

Before using it with an electron microscope, they use a very thin layer of gold to create conductivity in the sample, so that the photos have sufficient resolution. The sputter-coated with gold, in addition to the injection of gold on the sample, also applies a vacuum. In the case of higher than normal moisture, the sputter-coated with gold does not function properly. For this reason, flour sample was dried during $24 \mathrm{hrs}$ using the freeze dryer, FD-10V model, made in Iran. A thin layer of samples was fixed on the special aluminum bases by liquid glue. Then, the gold metal was spread on the samples by sputtercoated with gold. In this study, the device was a product of Bal-tec Company from Swiss. Samples that were completely covered by gold, transferred to the electron microscope with a maximum voltage of $30 \mathrm{KW}$. Also, the magnification was 1500 . In this study, scanning electron microscope (SEM) made by Philipps Company from Netherland, XL30 model, was used (Ahlborn et al., 2005).

\subsection{Producing dough and pan bread}

To produce bread dough, the below formula was used based on $100 \mathrm{~g}$ corn flour: flour $(100 \mathrm{~g})$, water $(100 \mathrm{~g}$ or equal to the weight of corn flour), salt (1.5g), sugar $(1 \mathrm{~g})$, albumin $(0.5 \mathrm{~g})$, lecithin powder $(0.75 \mathrm{~g})$, Saccharomyces cerevisiae yeast $(2 \mathrm{~g})$, and different levels of Balangu Shirazi gum (zero, one and two g). Samples were produced with two types of corn flour such as simple and pre-gelatinized. Table 1 shows the treatments in this study. To produce bread, first, all of the solid substances blended with each other and needed water added to it. The dough was mixed with 150 revolutions per minute during 10 mins and $1 \%$ oil added to the formulation in the sixth minute. The preliminary fermentation was performed in the fermentation container with $80 \%$ relatively moisture and $30^{\circ} \mathrm{C}$ temperature during 30 mins. Doughs were divided into $50 \mathrm{~g}$ pieces and placed in the template with $4 \mathrm{~cm}$ diameter and height. Final fermentation was carried out during 40 mins, $30^{\circ \mathrm{C}}$ temperature and $80 \%$ relative moisture. After steaming for 10s, baking was done in the rotary oven (Zuccihelliforni, Italy) for $20 \mathrm{mins}$ with $200^{\circ \mathrm{C}}$ temperature. After cooling, each sample was packed in polyethylene bags for the next examination and maintained at the ambient temperature $\left(25^{\circ \mathrm{C}}\right)$.

Table 1. Treatments containing two types of corn flour (simple and pre-gelatinized) and different levels of Balangu Shirazi gum

\begin{tabular}{|c|l|}
\hline \multicolumn{2}{|c|}{ Treatments } \\
\hline 1 & Corn flour \\
\hline 2 & Corn flour + 1\% Balangu gum \\
\hline 3 & Corn flour + 2\% Balangu gum \\
\hline 4 & Pre-gelatinization corn flour (PG-Corn) \\
\hline 5 & $\begin{array}{l}\text { Pre-gelatinization corn flour (PG-Corn) } \\
+1 \% \text { Balangu gum }\end{array}$ \\
\hline 6 & $\begin{array}{l}\text { Pre-gelatinization corn flour (PG-Corn) } \\
+2 \% \text { Balangu gum }\end{array}$ \\
\hline
\end{tabular}

\subsection{Moisture}

To do this examination, AACC 2000 standard with the number of 16-44 was used. For this purpose, samples were placed in the oven (Jeto tech, OF-O2G model, South Korea) during $2 \mathrm{hrs}$ interval with $100^{\circ \mathrm{C}}-105^{\circ \mathrm{C}}$ heat after baking.

\subsection{Porosity}

Image processing technique was used in order to evaluate the porosity amount of bread during $2 \mathrm{hrs}$ interval. For this purpose, a slice of bread with the dimension of $2 \times 2 \mathrm{~cm}$ was provided using the $120 \mathrm{~W}$ electric saw knife (41600 model). It was shot using the scanner (HP Scanjet G3010 model) and 300-pixel resolution. The produced picture was analyzed by Image $\mathbf{J}$ software (National Institutes Health, USA). Gray level images were produced with activating of a part bit of the software. To change gray level images to binary ones, binary Images section of software got activated. These images are a collection of bright and dark spots. Calculating the ratio of bright to dark points is 
estimated as an index for porosity amount of samples. It is obviously understood that the more proportion the more porosity of the achieved bread might exist (Naji-Tabasi and Mohebbi, 2015). With activating analysis part of the software, the ratio was calculated and porosity percent of samples was measured (Barcenas and Rosell, 2006; Sabanis et al., 2008).

\subsection{Specific volume}

Rapeseed replacement method was used according to AACC 2000 standard, 10-72 number, to measure specific volume. For this purpose, a piece of bread with the dimension of $2 \times 2 \mathrm{~cm}$ was produced from the geometric center of it during $2 \mathrm{hrs}$ interval after cooking and its specific volume was determined.

\subsection{Texture}

To perform a penetration test, texture analyzer QTS, CNS Farnell, UK model, was used during 2 and $72 \mathrm{hrs}$ after baking. The main purpose of this test is to determine required force for a distinguished compression. The amount of resistance is considered as an index of sample staling. AACC 2000 standard, 74-90 number, a method was used to do this test. For this purpose, a $25 \mathrm{~mm}$ sample was separated from a central part of the bread. The pressure test was done at the speed of $10 \mathrm{~mm}$ per minute using the related probe with $21 \mathrm{~mm}$ diameter. During the first compression, the obtained maximum power was considered as a bread firmness and resistance per Newton.

\subsection{Crust color evaluation}

The analysis of crust color was performed by assigning three indicators of $\mathrm{L}^{*}, \mathrm{a}^{*}$ and $\mathrm{b}^{*}$. $\mathrm{L}^{*}$ indicator shows the sample brightness and its domain is variable from zero (pure black) to 100 (pure white). $\mathrm{a}^{*}$ indicator shows that how the sample color is close to green and red colors. Its domain is variable from -120 (pure green) to +120 (pure red). $b^{*}$ indicator shows that how the sample color is close to blue and yellow colors. Its domain is variable from -120 (pure blue) to
+120 (pure yellow). To measure these indicators, first, a slice of bread crust was provided in a dimension of $2 \times 2 \mathrm{~cm}$ using the $120 \mathrm{~W}$ electric saw knife, 41600 model. It was shot by the scanner (HP Scanjet G3010) with 300-pixel resolution. Then, the pictures were analyzed by Image $\mathbf{J}$ software. With activating LAB space in the plugins part, the above indicators were calculated (Sun, 2008).

\subsection{Sensory test}

To do this, 10 referees were collected among the faculty members of Razavi Khorasan research and education center of agriculture and natural resources (Mashhad-Iran) based on Gacula and Singh method (1984) and triangle test. In this method, two identical and similar samples (control) are compared with one of the different treatments. After selecting a different sample and expressing the cause of the difference (better or worse), this sample is compared with the two samples, using the fivepoint hedonic method to this sample and each sensory characteristics in comparison with the points given to the sample. Then, sensory properties of bread were assessed in terms of shape (asymmetric shape, rupture or destruction of a part of bread and the existence of any hollow or internal space), the properties of upper surface (such as burn, unusual color, wrinkle and abnormal surface), the properties of bottom surface (like burn, wrinkle and abnormal surface), porosity (abnormal pore and more compression), texture firmness and softness (being dough or abnormal softness, being firmness and fragility and crispiness), chew ability (being dryness and firmness, being dough in the mouth and sticking to the teeth) and smell and taste (spicy taste, raw and rancidity smell and/or natural scent). These properties aren't effective equally. So, 4, 2, 1, 2, 2, 3 and 3 coefficient ranking was given to each property after studying references. Finally, total score (quality number of bread) was calculated using the below formula with having this information. The evaluation of properties was from very bad (1) to very good (5). Overall acceptance (quality 
number of bread) was calculated by Equation (1):

$$
\text { Equation (1) } \quad \mathrm{Q}=\frac{\sum(\mathrm{P} \times \mathrm{G})}{\sum \mathrm{P}}
$$

$\mathrm{Q}=$ Total acceptance (quality number of bread)

$\mathrm{P}=$ Coefficient of properties ranking

$\mathrm{G}=$ Coefficient of properties assessment

\subsection{Statistical analysis}

All samples were evaluated in three batches. In order comparison of the type of simple and microwave heated corn flour, as well as to determine the effects of Balangu Shirazi (Lallemantia Royleana) gum and to assess significant differences among treatments, a complete randomized design of triplicate analyses of six samples was performed using the Statistical Package for the Social Science (SPSS) 14.0 software (SPSS Inc., Chicago, IL, USA). The significant differences between the mean values of in the bread sample analyses were determined by using analysis of variance (ANOVA) independent t-test and Duncan's new multiple range tests were used to study the statistical differences of the means with $95 \%$ confidence.

\section{Results and discussions}

\subsection{The obtained images from the electronic microscope}

Figure 1 (A and B) shows the microscopic images of corn flour and pre-gelatinized corn flour with microwave, respectively. As the images show, granular structure of simple corn flour (unheated) is coherent and has a steadier surface while the structure of pre-gelatinized corn flour is destroyed due to microwave's heat. These granules have a more structural expansion and swell and, figure 1 (B) shows an uneven surface. In this regard, Majzoobi and Farahanky (2008) reported similar results and represented that starches which are influenced by thermal processes (electrical oven or microwave), their granular structure is destroyed whereby starches' molecules easily interact with the water. Also, Majzoobi and Farahanky (2010) reported that natural starch has a coherent granular structure and spherical shape and in an ambient temperature it's not able to absorb water and increase viscosity based on their own results of the paper. Further studies with electron microscopy on pre-gelatinization buckwheat flour with thermal processes (roasting, steaming, extrusion, boiling and microwave) (Sun et al., 2018), as well as corn flour and rice flour pre-gelatinised by microwave (Uthumporn et al., 2016), altered natural structure of starch granules was very distinct.

\subsection{Moisture}

The results of produced samples' moisture have shown in table 2 during 2 and $72 \mathrm{hrs}$ interval after baking. As results show, the moisture of samples containing pre-gelatinized corn flour is more than those which have simple corn flour. In addition, the results show that the increase of Balangu Shirazi gum formulation can cause an increase in produced samples' moisture. This samples' moisture was similar in both 2 and $72 \mathrm{hrs}$ interval after baking. The sample which contains pre-gelatinized corn flour and 2\% Balangu Shirazi gum has the most amount of moisture and has a similarity with a moisture of control sample (containing corn flour). It is likely that the higher amount of moisture in samples with pre-gelatinized corn flour is because of increasing water absorption than samples containing simple corn flour. This increase can be caused by the connection between water's molecules and starch chains (Tester and Karkalas, 1996). 

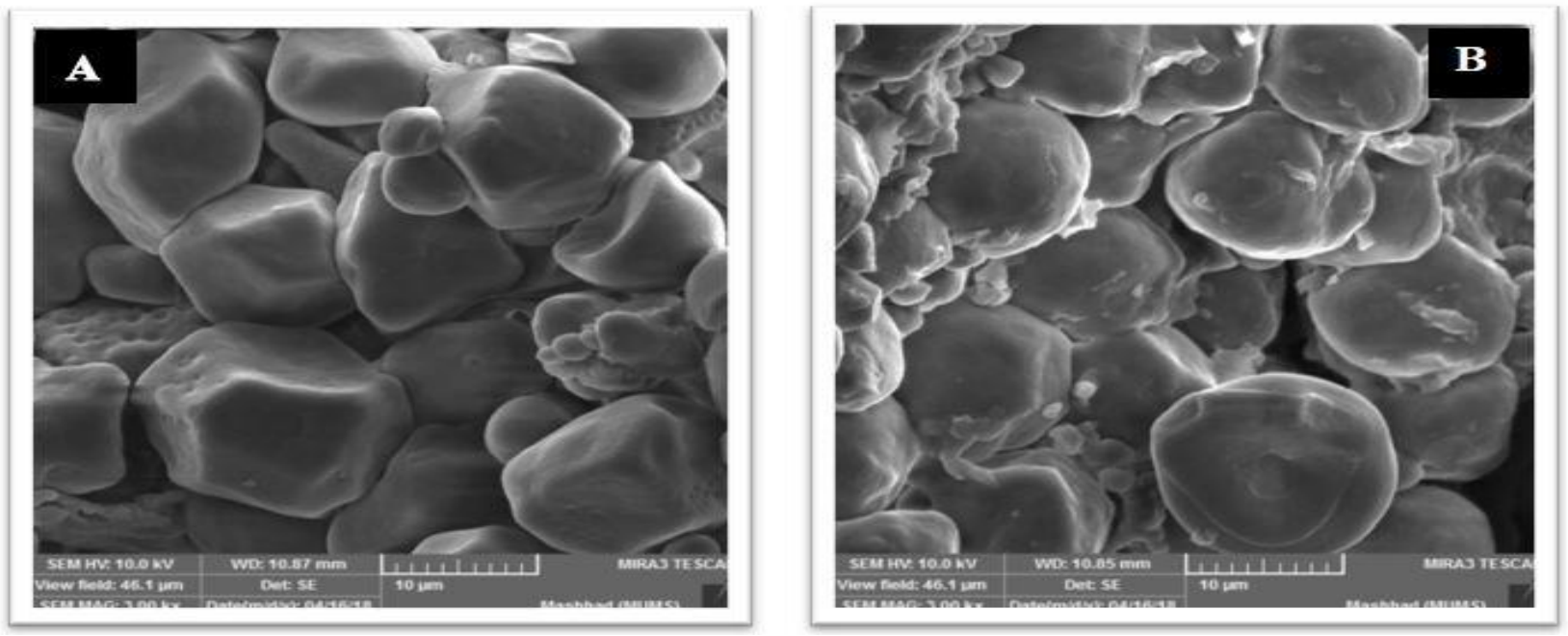

Figure 1. Microscopic images from corn flour (A) and pre-gelatinized corn flour with microwave (B)

On the other hand, heating up corn flour with microwave along with vibrational motions of water molecules can lead to more penetration of water into the starch's chains (Palav and Seetharaman, 2007). Moreover, Majzoobi and Farahanky (2008) presented that starches which are influenced by thermal processes, their granular structure is destroyed and starches' molecules interact with the water easily and result in increased absorption of water of dough and increased the moisture of final product. In a way of increasing amount of moisture with an increased amount of gum in a formulation of bread, Sahraiyan et al. (2013) presented that increased water maintenance capacity in gums is due to hydrophilic properties and existence of hydroxyl groups in gums' structure. In addition, McCarthy et al. (2005) reported that gums interact with the water because of a hydrophilic essence and decrease water release and strengthen the presence of water into the system by which water absorption is increased and the moisture of final product is maintained after the baking process.

Table 2. The effect of corn flour (simple and pre-gelatinized) and different levels of Balangu Shirazi gum on the moisture of gluten-free bread during 1- and 3-day interval after baking

\begin{tabular}{|c|c|c|c|}
\hline & Treatment & \multicolumn{2}{|c|}{ Moisture } \\
\cline { 2 - 4 } & & First day & Third day \\
\hline 1 & Corn flour & $14.8 \pm 0.2^{\mathrm{f}}$ & $9.7 \pm 0.3^{\mathrm{e}}$ \\
\hline 2 & Corn flour+1\% Balangu gum & $19.7 \pm 0.0^{\mathrm{d}}$ & $14.8 \pm 0.4^{\mathrm{c}}$ \\
\hline 3 & Corn flour+2\% Balangu gum & $21.4 \pm 0.5^{\mathrm{b}}$ & $17.9 \pm 0.5^{\mathrm{b}}$ \\
\hline 4 & Pre-gelatinization corn flour & $17.4 \pm 0.5^{\mathrm{e}}$ & $13.4 \pm 0.3^{\mathrm{d}}$ \\
\hline 5 & $\begin{array}{c}\text { Pre-gelatinization corn } \\
\text { flour+1\% Balangu gum }\end{array}$ & $20.6 \pm 0.3^{\mathrm{c}}$ & $15.1 \pm 0.3^{\mathrm{c}}$ \\
\hline 6 & $\begin{array}{c}\text { Pre-gelatinization corn } \\
\text { flour+2\% Balangu gum }\end{array}$ & $22.5 \pm 0.2^{\mathrm{a}}$ & $19.4 \pm 0.5^{\mathrm{a}}$ \\
\hline
\end{tabular}

Similar words in each column don't have a significant difference statistically in $P<0.05$ level. 
In a review by Kang et al. (2018) which was used in combination with modified starches and gums for the production of bread, it was found that the interaction of water with starch was higher than that of water with flour, due to the migration of moisture inside bread and the achievement of equilibrium during storage can affect bread's longer shelf life.

\subsection{Porosity}

Figure 2 shows the results of produced samples' porosity. According to the results, samples containing pre-gelatinized corn flour and $1 \%$ and $2 \%$ Balangu Shirazi gum have most porosity among produced samples. The porosity amount of these two samples doesn't have a significant difference $(\mathrm{P}<0.05)$. But the porosity in a sample containing corn flour and $2 \%$ gum is more than $1 \%$. It shows that gelatinization of flour or starch in a formulation of gluten free bread is associated with a decreased gum. It is more likely that increased dough viscosity can cause decrease of consumable gum in case of using the gelatinized flour. Ziobro et al. (2012) found similar results based on a study of the effect of modified starches on gluten-free bread and dough properties and said that use of modified starch could cause an increased amount of porosity than simple starch in glutenfree products formulation by decreasing size, increasing gas cells and their homologous distribution in product texture. In addition, corn starch contains about 25\% amylose and $75 \%$ amylopectin, because amylopectin, due to its lateral branches, can improve the volume, increase the smoothness of gaseous cells and porosity, and ultimately create a coherent structure in the final product (Lopez et al., 2004; Rathnatake et al., 2018).

Another important parameter of the kernel of bakery products is porosity. It totally implies the pore structure in the kernel of this category of foodstuffs and is an effective factor in qualitative properties of products kernel in baking industries (Armero and Collar, 1996). The porosity of texture kernel is impressed by the number of hollows in the kernel of texture and their distribution. The porosity amount of final product will be more if the number of hollows and gas cells are more and their distribution is more homolog. In a study conducted by Ozkocozge et al. (2009), it was presented if gums are used in desirable levels in formulation of foodstuffs so that they don't disturb the distribution of existing air bubbles in the sample, they strengthen the gas cells by decreased connection of gas cells due to making a thick layer on the surface of cells. So, each cell remains separately and its size is smaller. This issue has an impressive effect on increased porosity. In this study, it seems that the best result has been obtained for porosity using the gelatinized corn flour and 1\% Balangu Shirazi gum. It means that the produced product has a desirable number of gas cell (by maintenance the gas cells in the dough and during the baking process) and homologous distribution of these cells in gluten-free bread. 


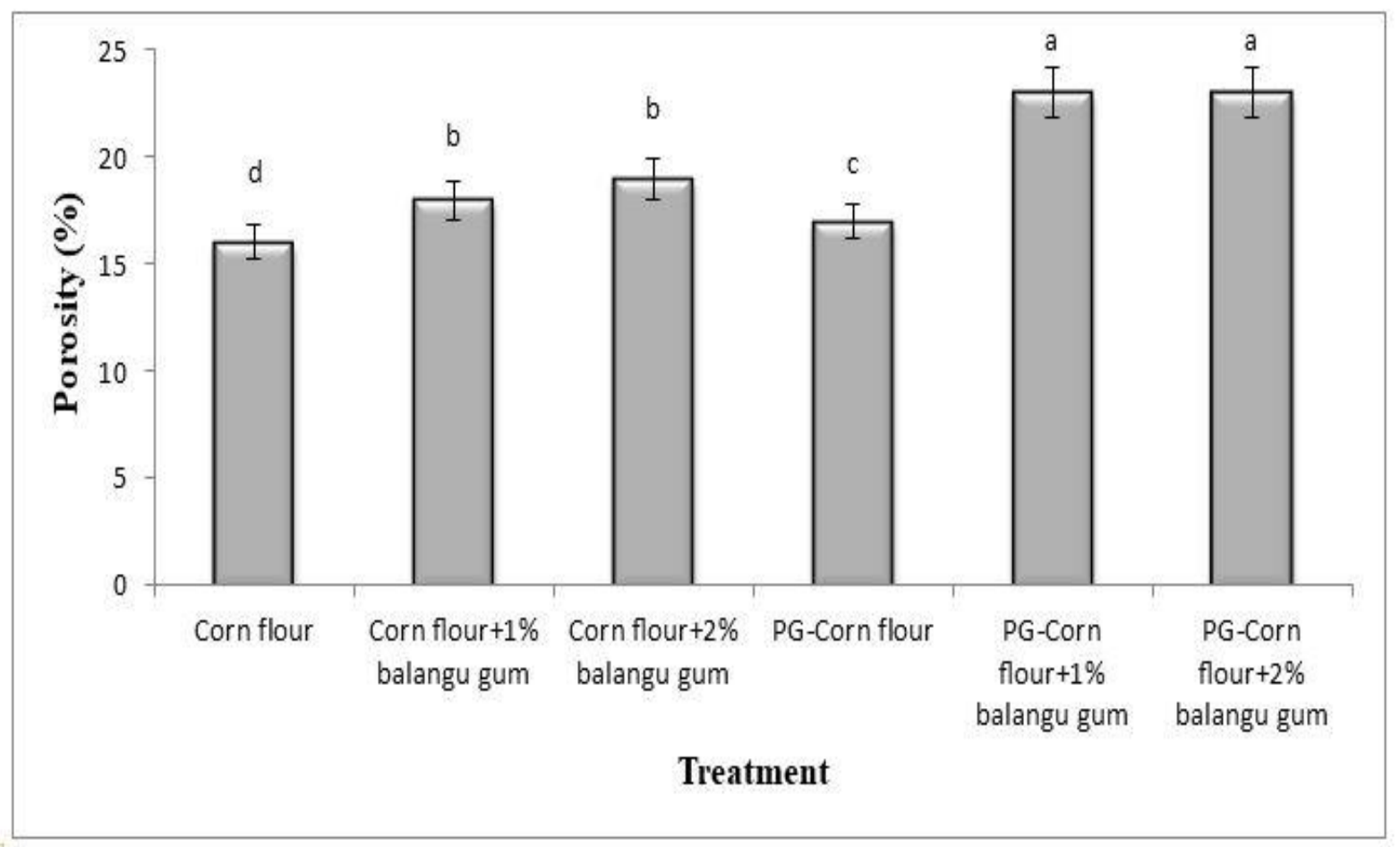

Figure 2. The effect of corn flour (simple and pre-gelatinized) and different levels of Balangu Shirazi gum on the porosity of gluten-free bread

Similar words in each column don't have a significant difference statistically in $P<0.05$ level.

\subsection{Specific volume}

Table 3 shows the results of the specific volume of produced samples. Based on results, samples containing pre-gelatinized corn flour with $1 \%$ and $2 \%$ Balangu Shirazi gum have the most amount of specific volume among produced samples. As results show, samples containing pre-gelatinized corn flour have more specific volume. Also, the results demonstrate that there isn't a significant difference in specific volume of produced samples with adding $1 \%$ or $2 \%$ Balangu Shirazi gum to a formulation of gluten-free bread $(\mathrm{P}<0.0 .5)$.

The specific volume of gluten-free bread or breads containing weak flour depends on several factors. One of these factors is the activity of bakery yeast and production of a desirable number of gas cells by the yeast. The second factor is the maintenance of gas cells in bread dough and prevention from their exit before baking process. Dough viscosity in a cold water can be an important factor in this regard. The third factor is to maintain the gas cells during the baking process. The wall of existing gas cells in gluten-free bread dough is strengthened during this process. Increased temperature causes the expansion of gas cells. If the wall doesn't have a good resistance, cells are ruptured and several gas cells join each other and the final product doesn't have a good volume (Sahraiyan et al., 2013). Therefore, given the reports by Sahraiyan et al. (2013), it seems that heated corn flour in the microwave (gelatinized corn flour) has a more viscosity of cold water and could maintain the number of gas cells with increasing viscosity. In this regard, Majzoobi and Farahanky (2010) reported that natural starch is not able to absorb water and increase viscosity because of coherent granular structure in ambient temperature while in thermal processes, the viscosity is made in the cold water due to gelatinizing starch. In addition, Majzoobi and Farahanky (2008) presented that starches which are influenced by thermal processes, their 
granular structure is destroyed and starch's molecules interact with the water easily and cause the increase of viscosity in an ambient temperature. Balangu Shirazi gum can strengthen the wall of gas bubbles and prevent from their rupture during the baking process. In this study, it's observed that there's not a significant difference between samples containing $1 \%$ and $2 \%$ gum $(\mathrm{P}<0.05)$. It shows that produced samples need to most volume to achieve $1 \%$ gum. Even it's possible the volume of sample is decreased with increasing gum more than $2 \%$. Because the wall of gas cells becomes thick and strong and prevents from the expansion caused by increased temperature during the baking process. In this regard, Shittu and Abulud (2009) reported similar results and represented that the exact consumable level of gum is essential in bakery products because if the right concentration is chosen given the formulation, the gas maintenance ability is increased by raising the stability and permeability of the wall of gas cells. If the use of this gum is more than required need, it acts reversely. Reducing volumes as a result of excessive gum consumption is due to the increased consistency and increased elasticity, whereby gaseous cells can not be well bonded, grow and affect the increase of the specific volume of the product (Yaseen et al., 2010; Bourekoua et al., 2016).

Table 3. The effect of corn flour (simple and pre-gelatinized) and different levels of Balangu Shirazi gum on specific volume and stiffness of gluten-free bread texture during 1- and 3-day interval after baking

\begin{tabular}{|c|c|c|c|c|}
\hline & \multirow[t]{2}{*}{ Treatment } & \multirow{2}{*}{$\begin{array}{l}\text { Specific volume } \\
(\mathrm{Cm} 3 / \mathrm{g})\end{array}$} & \multicolumn{2}{|c|}{ Firmness (N) } \\
\hline & & & First day & Third day \\
\hline 1 & Corn flour & $1.9 \pm 0.2^{\mathrm{c}}$ & $11.9 \pm 0.4^{\mathrm{a}}$ & $22.5 \pm 0.2^{\mathrm{a}}$ \\
\hline 2 & $\begin{array}{c}\text { Corn flour+1\% Balangu } \\
\text { gum }\end{array}$ & $3.1 \pm 0.4^{b}$ & $7.1 \pm 0.5^{c}$ & $10.7 \pm 0.4^{\mathrm{c}}$ \\
\hline 3 & $\begin{array}{c}\text { Corn flour }+2 \% \text { Balangu } \\
\text { gum }\end{array}$ & $3.2 \pm 0.2^{b}$ & $8.0 \pm 0.3^{b c}$ & $10.5 \pm 0.7^{c}$ \\
\hline 4 & $\begin{array}{l}\text { Pre-gelatinization corn } \\
\text { flour }\end{array}$ & $2.1 \pm 0.2^{c}$ & $9.2 \pm 0.4^{b}$ & $18.2 \pm 0.4^{b}$ \\
\hline 5 & $\begin{array}{l}\text { Pre-gelatinization corn } \\
\text { flour }+1 \% \text { Balangu gum }\end{array}$ & $5.1 \pm 0.5^{\mathrm{a}}$ & $4.9 \pm 0.2^{d}$ & $8.6 \pm 0.4^{\mathrm{d}}$ \\
\hline 6 & $\begin{array}{l}\text { Pre-gelatinization corn } \\
\text { flour }+2 \% \text { Balangu gum }\end{array}$ & $4.9 \pm 0.4^{\mathrm{a}}$ & $4.8 \pm 0.1^{\mathrm{d}}$ & $6.5 \pm 0.9^{\mathrm{e}}$ \\
\hline
\end{tabular}

Similar words in each column don't have a significant difference statistically in $P<0.05$ level.

\subsection{Texture}

The results of texture firmness have shown in table 3 during 2 and $72 \mathrm{hrs}$ interval after baking. Based on results, samples containing pre-gelatinized corn flour with $1 \%$ and $2 \%$ Balangu Shirazi gum have the minimum amount of texture firmness among produced samples during $2 \mathrm{hrs}$ interval after baking. Also, the results of texture firmness during $72 \mathrm{hrs}$ interval after baking show that sample containing pre- gelatinized corn flour and 2\% Balangu Shirazi gum has a minimum amount of texture firmness. It's needed to be mentioned that the firmness of all produced samples was raised during $72 \mathrm{hrs}$ maintenance.

It seems that the reason of superiority of pregelatinized corn flour with the microwave than simple corn flour is that exertion of heat on corn flour and production of pre-gelatinized corn flour increases the expansion of molecular 
structure of starch in the water. It leads to more penetrate water into the starch network and improve the interactions of starch with the water. It could be expected that the final product has a soft texture with increased interaction of starch with the water and the maintenance of product's moisture. In this regard, Jiang et al. (2011) reported similar results with studying the physicochemical properties of the starch gel of rice. The texture firmness of products of baking industries depends on factors like the maintenance of product's moisture during the baking process and some technologic properties such as volume and porosity immediately after baking. The maintenance of moisture prevents from firmness and frangibility and the texture of product becomes softer after baking. On the other hand, two impressive factors that influence texture softness and decreased compression are increased volume and porosity due to the presence of a numerous number of air bubbles in the product and equal distribution of them. So, it's expected that samples with most moisture, volume and porosity have a fewer firmness.

Bread production and storage, especially based on starch, has led to numerous structural changes that ultimately lead to product destruction. These changes are mainly due to the immigration of water from crumb to crust and hardening of starch granules. Additives such as gum can be used to reduce this undesirable phenomenon (Horstmann et al., 2017; Gao et al., 2018; Witczak et al., 2019). Many searches have been conducted about using the gum in glutenfree products. In studies conducted by Moreira et al. (2013), Crockett et al. (2011), Demirkesen et al. (2010) and Onyango et al. (2009), similar results have been reported based on the decreased firmness of texture of produced products with adding $1 \%$ and $2 \%$ gum to a formulation of gluten-free products. Staling and increased firmness of bread that are started immediately after baking and increased during maintenance is a complicated process.

Several factors like amylopectin retrogradation, polymers rearrangement in an amorphous area, decreased moisture and/or distribution of moisture between amorphous and crystal areas are involved in this process (Ahlborn et al., 2005). Any kind of additives that can prevent from these factors especially decreased moisture and its immigration from internal texture to the crust, decrease the texture firmness during a maintenance period. It seems that the presence of Balangu Shirazi gum can prevent from an abnormal increase of product with the maintenance of moisture in internal gluten-free bread texture. Ribotta et al. (2004) attributed the increased firmness to bread moisture migration from the crumb to crust and recrystallization of starch in the absence of gum in a formulation of bakery products.

\subsection{Crust color evaluation}

The results of continuous colorful components $\left(\mathrm{L}^{*} \mathrm{a}^{*} \mathrm{~b}^{*}\right)$ have shown in table 4 . The results of this section show that use of pregelatinized corn flour and increased level of consumption of Balangu Shirazi gum in a formulation of gluten-free bread cause the increase of $\mathrm{L}^{*}$ colorful component. The presence of Balangu Shirazi gum didn't have a significant effect on two $\mathrm{a}^{*}$ and $\mathrm{b}^{*}$ colorful components $(\mathrm{P}<0.05)$ while the use of pre-gelatinized corn flour results in the decrease of $b^{*}$ colorful component. Purlis and Salvadori (2009) represented that crust surface changes are responsible for crust brightness and soft and regular surfaces have more ability to increase $\mathrm{L}^{*}$ colorful component of crust than wrinkled surfaces. Obtaining these results weren't unexpected because samples containing pregelatinized corn flour and Balangu Shirazi gum were effective in making an equal flat surface with the maintenance of moisture during baking process and prevention from rapid immigration from internal texture to the crust. Color as one of the fundamental parameters may be influenced by factors such as process conditions, formulation and even the presence of specific materials (Marti et al., 2016). Also, it should be mentioned that texture properties like volume, porosity and texture firmness can affect the surface of final product except for the 
maintenance of moisture. If the number of gas hollows is few, the extent of hollows is larger and their distribution is unequal and the texture firmness was more, light reflection is fewer from the surface because of excessive compression of sample surface and existence of large hollows in the surface. So, the glitter of a sample or $\mathrm{L}^{*}$ colorful component is decreased.

Similar results were reported about increased glitter by adding garden cress gum to the bread containing wheat and rice flour in a Sahraiyan et al's study (2013) and adding xanthan gum to gluten free bread in a
Mohammadi et al's study (2014). On the other hand, Phattanakulkaewmorie et al. (2011) said that the presence of pigments and fibers in the flour and interaction that happens among components in formulation during producing dough and baking product are effective factors on $\mathrm{a}^{*}$ and $\mathrm{b}^{*}$ colorful components. It seems that the exertion of heat on corn flour and production of pre-gelatinized corn flour causes a decrease of yellow pigments in the flour. Consequently, $b^{*}$ colorful component in gluten-free samples producing from this type of flour has decreased.

Table 4. The effect of corn flour (simple and pre-gelatinized) and different levels of Balangu Shirazi gum on the color of gluten-free bread

\begin{tabular}{|c|c|c|c|c|}
\hline & Treatment & \multicolumn{3}{|c|}{ Crust color value } \\
\cline { 3 - 4 } & & $\mathbf{L}^{*}$ & $\mathbf{a}^{* \mathbf{n s}}$ & $\mathbf{b}^{*}$ \\
\hline 1 & Corn flour & $31.6 \pm 0.7^{\mathrm{e}}$ & $11.2 \pm 0.5$ & $24.2^{*} \pm .9^{\mathrm{a}}$ \\
\hline 2 & Corn flour+1\% Balangu gum & $39.2 \pm 0.4^{\mathrm{c}}$ & $11.7 \pm 0.8$ & $24.8 \pm 0.3^{\mathrm{a}}$ \\
\hline 3 & Corn flour+2\% Balangu gum & $42.8 \pm 1.5^{\mathrm{b}}$ & $11.2 \pm 2.3$ & $24.1 \pm 0.7^{\mathrm{a}}$ \\
\hline 4 & Pre-gelatinization corn flour & $36.4 \pm 0.8^{\mathrm{d}}$ & $12.5 \pm 1.2$ & $22.5 \pm 0.5^{\mathrm{b}}$ \\
\hline 5 & $\begin{array}{c}\text { Pre-gelatinization corn } \\
\text { flour+1\% Balangu gum }\end{array}$ & $42.2 \pm 0.6^{\mathrm{b}}$ & $10.5 \pm 0.7$ & $22.3 \pm 0.3^{\mathrm{b}}$ \\
\hline 6 & $\begin{array}{c}\text { Pre-gelatinization corn } \\
\text { flour+2\% Balangu gum }\end{array}$ & $48.2 \pm 0.8^{\mathrm{a}}$ & $9.8 \pm 1.2$ & $22.5 \pm 0.2^{\mathrm{b}}$ \\
\hline
\end{tabular}

Similar words in each column don't have a significant difference statistically in $P<0.05$ level. $n s^{*}:$ Produced samples don't have a significant difference statistically in $P<0.05$ level.

\subsection{Overall acceptance}

The score of overall acceptance of glutenfree pan breads has shown in figure 3. Sensory evaluators gave the score of overall acceptance to the samples containing pre-gelatinized corn flour and $1 \%$ and $2 \%$ Balangu Shirazi gum. The score of overall acceptance of these two samples didn't have a significant difference $(\mathrm{P}<0.05)$. Given the studied properties, obtaining this result wasn't unexpected. Taste referees gave the most score of porosity, texture softness and firmness, chew ability and shape to the samples containing pre-gelatinized corn flour and $1 \%$ and $2 \%$ Balangu Shirazi gum that affect the score of overall acceptance. The score of the properties of the upper and bottom surface is influenced by the color of the product greatly. Sensory evaluators gave the most score to the two mentioned samples in terms of surface properties. Given the results of colorful component evaluation of the crust, obtaining this score was predictable because these two samples had a high glitter. Also, samples containing pregelatinized corn flour and $1 \%$ and $2 \%$ Balangu Shirazi gum had desirable smell

and taste. It's likely that improvement of texture (firmness and softness, porosity and chew ability) in these two samples and perception of better feeling during chewing cause desirable 
smell and taste. In this regard, many searches have been performed to study the effective factors on a release of taste. Most researches believed that perception of taste severity and release of tasty substances depends on the type of final texture of a product (Koliandris et al., 2008). For instance, a perception of the taste has been reported better in the texture having desirable firmness, cohesion, and coherence. The cause of this issue was the different interaction between tasty substance and texture structure according to Boland et al's study (2004). In researches on the production of gluten-free bread based on pea flour Mastromatteo et al. (2015) and small broken rice berry flour (Numfon, 2017), addition of gum increased the parameters such as porosity, specific volume, texture, crust color, chew ability, and sensory properties so that the most score of overall acceptance was attributed to gum samples.

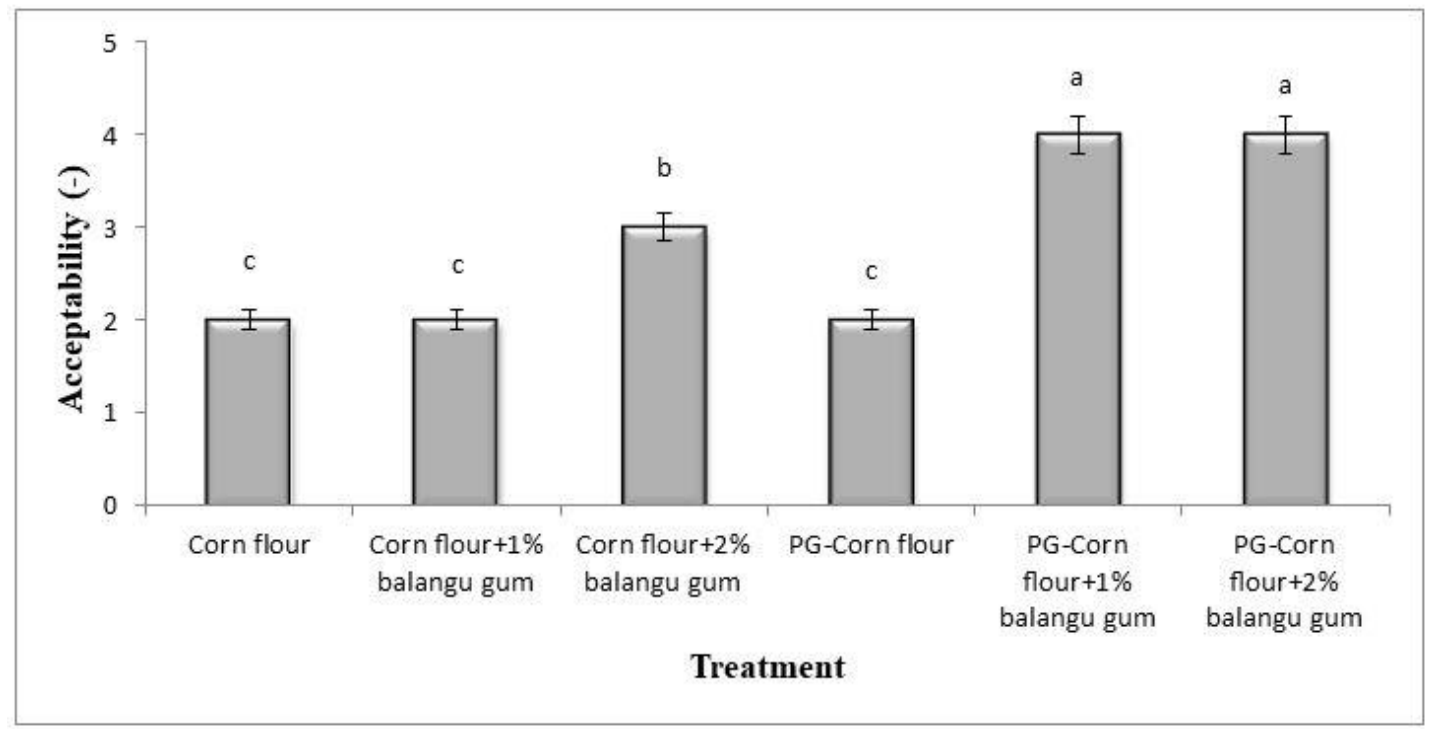

Figure 3. The effect of corn flour (simple and pre-gelatinized) and different levels of Balangu Shirazi gum on the overall acceptance score of gluten-free bread

Similar words in each column don't have a significant difference statistically in $P<0.05$ level.

\section{Conclusions}

Based on the results of this study, it could be said that pre-gelatinized corn flour is effective in increasing specific volume, porosity, and softness of gluten-free pan bread texture. In addition, high-quality gluten-free bread can be produced using the pre-gelatinized corn flour and $1 \%$ local gum of Balangu Shirazi which has a good marketing. Taste referees gave the highest score of overall acceptance to this sample and presented that sample containing pre-gelatinized corn flour and $1 \%$ local gum of Balangu Shirazi has a new and desirable smell and taste which is attractive for a consumer.

\section{References}

AACC. (2000). Approved methods of the American Association of Cereal Chemists, Vol. 2., 10th (Ed.). American Association of Cereal Chemists, St. Paul, MN.

Ahlborn, G.J., Pike, O.A., Hendrix, S.B., Hess, W.M., Huber, C.S. (2005). Sensory, mechanical and microscopic evaluation of staling in low protein and gluten-free bread. Cereal Chemistry, 82, 328-335.

Anastasiades, A., Thanou, S., Loulis, D., Stapatoris, A., Karapantsios, T.D. (2002). Rheological and physical characterization of pre-gelatinization maize starches. Journal of Food Engineering, 52, 57-66. 
Anderson, A.K., Guraya, H.S. (2006). Effects of microwave heat-moisture treatment on properties of waxy and non-waxy rice starches. Food Chemistry, 97, 318-323.

Armero, E., Collar, C. (1996). Anti-stailing additives, flour type and sourdough process effects on functionality of wheat doughs. Journal of food science, 61(2), 299-303.

Barcenas, M.E., Rosell, C.M. (2006). Different approaches for improving the quality and extending the shelf life of the partially baked bread: Low temperatures and HPMC addition. Journal of Food Engineering, 72, 92-99.

Bilbao-Sainz, C., Butler, M., Weavar, T., Bent, J. (2007). Wheat starch gelatinization under microwave irradiation and conduction heating. Carbohydrate Polymers, 69, 224232.

Boland, B., Buhr, K., Giannouli, P., Van Ruth, S.M. (2004). Influence of gelatin, starch, pectin and artificial saliva on the release of 11 flavor compounds from model gel systems. Food Chemistry, 86, 401-411.

Bourekoua, H., Benatallah, L., Zidoune, M.N., Rosell, C.M. (2016). Developing gluten free bakery improvers by hydrothermal treatment of rice and corn flours. LWT-Food Science and Technology, 73, 342-350.

Crockett, R., Ie, P., Vodovotz, Y. (2011). Effects of soy protein isolate and egg white solids on the physicochemical properties of glutenfree bread. Food Chemistry, 129(1), 84-91.

Demirkesen, I., Mert, B., Sumnu, G., Sahin, S. (2010). Rheological properties of glutenfree bread formulation. Journal of Food Engineering, 96(2), 295-303.

Gacula, J.R., Singh, J. (1984). Statistical methods in food and consumer research. U.S.A, Academic Press Inc., (pp. 360-366).

Gallagher, E., Kunkel, A., Gormley, T.R., Arendt, E. (2004). The effect of dairy and rice powder addition on loaf and crumb characteristics and shelf life (intermediate and long term) of gluten-free bread stored in modified atmosphere. Food Research Technology, 218, 44-48.
Gao, Y., Janes, M.E., Chaiya, B., Brennan, M.A., Brennan, C.S., Prinyawiwatkul, W. (2018). Gluten-free bakery and pasta products: prevalence and quality improvement. International Journal of Food Science and Technology, 53, 19-32.

Hamaker Bruce, R. (2008). Technology of functional cereal products. Woodhead publishing limited, (pp. 397-448).

Horchani, H., Chaabouni, M., Gargouri, Y., Sayari, A. (2010). Solvent-free lipasecatalyzed synthesis of long-chain starch esters using microwave heating: Optimization by response surface methodology. Carbohydrate Polymers, 79(2), 466-474.

Horstmann, S.W., Lynch, K.M., Arendt, E.K. (2017). Starch characteristics linked to gluten-free products. Foods, 6, 29.

Jiamjariyatam, R., Kongpensook, V., Pradipasena, P. (2015). Effects of amylose content, cooling rate and aging time on properties and characteristics of rice starch gels and puffed products. Journal of Cereal Science, 61, 16-25.

Jiang, Q., Xu, X., Jin, Z., Tian, Y., Hu, X., Bai, Y. (2011). Physico-chemical properties of rice starch gels: Effect of different heat treatments. Journal of Food Engineering, 107, 353-357.

Joshi, N.D., Mohapatra, D., Joshi, D.C. (2014). Varietal selection of some indica rice for production of puffed rice. Food and Bioprocess Technology, 7, 299-305.

Kang, N., Reddy, C.K., Park, E.Y., Choi, H.D., Lim, S.T. (2018). Antistaling effects of hydrocolloids and modified starch on bread during cold storage. LWT-Food Science and Technology, 96, 13-18.

Koliandris, A., Lee, A., Ferry, A., Hill, S., Mitchell, J. (2008). Relationship between structure of hydrocolloid gels and solutions and flavor release. Food Hydrocolloids, 22, 623-630.

Lopez, A.C.B., Pereira, A.J.G., Junqueira, R.G. (2004). Flour mixture of rice flour, corn and cassava starch in the production of gluten 
free white bread. Brazilian Archives of Biology and Technology, 47, 63-70.

Majzoobi, M., Farahanky, A. (2008). Changes in molecular structure and physicochemical properties of wheat starch affected by high temperature and shear. Journal of Science and Technology of Agriculture and Natural Resources, 12(43), 335-347.

Majzoobi, M., Farahanky, A. (2010). Comparison of the effects of extrusion cooking on some cereal starches. International Journal of Food Engineering, 6, 1556-1559.

Marti, A., D’Egidio, M.G., Pagani, M.A. (2016). Pasta: quality testing methods. In: C. Wrigley, H. Corke, K. Seetharaman, F. Faubion (eds), Encyclopedia of cereal grains. (2nd ed.). (p. 161-165), London, Academic Press Inc.

Mastromatteo, M., Danza, A., Lecce, L., Spinelli, S., Lampignano, V., Laverse, J., Conte, A., Del nobile, M.A. (2015). Nutritional and physicochemical characteristics of whole meal bread enriched with pea flour. International Journal of Food Science + Technology, 50(1), 92-102.

McCarthy, D.F., Gallagher, E., Gormley. T.R., Schober, T.J., Arenth, E.K. (2005). Application of response surface methodology in the development of glutenfree bread. Cereal Chemistry, 82, 609-615.

Mohammadi, M., Sadeghnia, M., Azizi, M.H., Neyestani, T.R., Morta Zavian, A.M. (2014). Development of Gluten-free flat bread using by hydrocolloids. Xanthan and CMC. Journal of Industrial and Engineering Chemistry, 20(4), 1812-1818.

Moreira, R., Chenlo, F., Torres, M.D. (2013). Effect of chia (Sativa hispanica L.) and hidrocolloids on rheology of gluten-free doughs based on chestnut flour. LWT-Food Science and Technology, 50(1), 160-166.

Naghibi, F., Mosaddegh., M., Mohammadi, S., Ghorbani, A. (2005). Labiatae family in folk medicine in Iran: from ethanobotany to pharmacology. Iranian Journal of Pharmaceutical Research, 2, 63-79.
Naji-Tabasi, S., Mohebbi, M. (2015). Evaluation of cress seed gum and xanthan gum effect on macrostructure properties of gluten-free bread by image processing. Journal of Food Measurement and characterization, 9, 110-119.

Ndife, M., Sumnu, G., Bayindirli, L. (1998). Differental scanning calorimetry determination of gelatinization rates in different starches due to microwave heating. LWT- Food Science and Technology, 31, 484-488.

Numfon, R. (2017). Effects of different hydrocolloids on properties of gluten-free bread based on small broken rice berry flour. Food Science and Technology International, 23(4), 310-317.

Onyango, C., Unbehend, G., Lindhauer, M.G. (2009). Effect of cellulose-derivatives and emulsifiers on creep-recovery and crumb properties of gluten-free bread prepared from sorghum and gelatinized cassava starch. Food Research International, 42, 949-955.

Ozkocozge, S., Summe, G., Sahin, S. (2009). The effect of gums on macro and microstructure of breads baked in different ovens. Food hydrocolloids, 23, 2182-2189.

Palav, T., Seetharaman, K. (2007). Impact of microwave heating on the physicochemical properties of a starch-water model system. Carbohydrate Polymers, 67, 569-604.

Phattanakulkaewmorie, M., Paseephol, T., Moongngram, A. (2011). Chemical properties of malted sorghum flour and characteristics of gluten free bread. World Academy of Science, Engineering and Technology, 57, 457-460

Purlis, E., Salvadori, V. (2009). Modelling the browning of bread during baking. Food Research International, 42, 865-870.

Rathnatake, H.A., Navaratne, S.B., Navaratne, C.M. (2018). Porous crumb structure of Leavened baked products. International Journal of Food Science, 2018, Article ID: 8187318. 
Razavi, S.M.A., Karazhiyan, H. (2009). Flow properties and thixotropy of selected hydrocolloids, Experimental and modeling studies. Food Hydrocolloids, 23(3), 908912.

Razavi, S.M.A., Mohammadi Moghadam, T., Mohammad Amini, A. (2008). Physicomechanic and chemical properties of Balangu seed. International Journal of Food Engineering, 4 (5), Article 4.

Ribotta, P.D., Ausar, S.F., Morcillo, M.H., Perez, G.T., Beltramo, D.M., Leon, A.E. (2004). Production of gluten-free bread using soybean flour. Journal of Science Food Agriculture, 84, 1969-1974.

Sabanis, D., Tzia, C., Papadakis, S. (2008). Effect of different raisin juice preparations on selected properties of gluten-free bread. Food and Bioprocess Technology, 1, 374383.

Sahraiyan, B., Naghipour, F., Karimi, M., Ghiafeh Davoodi, M. (2013). Evaluation of Lepidium sativum seed and guar gum to improve dough rheology and quality parameters in composite rice-wheat bread. Food Hydrocolloid, 30, 698-703.

Shittu, T.A., Abulud, E.O. (2009). Functional effects of Xanthan gum practice and research clinical. Gastroenterologye, 19(3), 359-371.

Sun, D. (2008). Computer vision technology for food quality evaluation. New York, Academic Press.

Sun, X., Li, W., Hu, Y., Zhou, X., Ji, M., Yu, D., Fujita, K., Tatsumi, E., Luan, G. (2018). Comparison of pregelatinization methods on physicochemical, functional and structural properties of tartary buckwheat flour and noodle quality. Journal of Cereal Science, 80, 63-71.

Swinkels, J.J.M. (1985). Composition and properties of commercial native starches. Starch /Starke, 37(1), 1-5.

Tester, R.F., Karkalas, J. (1996). Swelling and gelatinization of starches. Cereal Chemistry, 73, 271-277.
Uthumporn, U., Nadiah, N.I., Koh, W.Y., Zaibunnisa, A.H., Azwan, L. (2016). Effect of microwave heating on corn flour and rice flour in water suspension. International Food Research Journal, 23(6), 2493-2503.

Vadivambal, R., Jayas, D.S. (2007). Changes in quality of microwave-treated agricultural products-a review. Biosystems Engineering, 98, 1-16.

Witczak, M., Korus, J., Ziobro, R., Juszczak, L. (2019). Waxy starch as dough component and anti-staling agent in gluten-free bread. LWT-Food Science and Technology, 99, 476-482.

Yaseen, A.A., Shouk, A.H., Ramadan, M.T. (2010). Corn-wheat pan bread quality as affected by hydrocolloids. Journal of American Science, 6(10), 684-690.

Zhongdong, L., Peng, L., Kennedy, J.F. (2005). The technology of molecular manipulation and modification assisted by microwaves as applied to starch granules. Carbohydrates Polymers, 61, 374-378.

Ziobro, R., Korus, J., Witczak, M., Juszczak, L. (2012). Influence of modified starches on properties of gluten-free dough and bread. Part II: Quality and staling of gluten-free bread. Food Hydrocolloids, 29(1), 68-74.

Zylema, B.J., Grider, J.A., Gordan, J., Davis, E.A. (1985). Model wheat starch systems heated by microwave irradiation and conduction with equalized heating times. Cereal Chemistry, 62, 447-453. 